Research, Society and Development, v. 9, n. 7, e911974183, 2020

(CC BY 4.0) | ISSN 2525-3409 | DOI: http://dx.doi.org/10.33448/rsd-v9i7.4183

\title{
Abordagens qualitativas em estudos sobre pobreza: uma revisão estruturada da literatura
}

Qualitative approaches in poverty studies: a structured literature review

Enfoques cualitativos en estudios sobre la pobreza: una revisión estructurada de la literatura

Recebido: 02/05/2020 | Revisado: 04/05/2020 | Aceito: 04/06/2020 | Publicado: 16/06/2020

Francis Régis Gonçalves Mendes Barbosa

ORCID: https://orcid.org/0000-0003-4462-7668

Universidade Estadual de Mato Grosso do Sul, Brasil

E-mail: francis_barbosa@hotmail.com

Maiara de Oliveira Noronha

ORCID: https://orcid.org/0000-0002-7525-2996

Universidade Estadual do Oeste do Paraná, Brasil

E-mail: mai.ol.noronha@gmail.com

Moacir Piffer

ORCID: https://orcid.org/0000-0003-3937-0941

Universidade Estadual do Oeste do Paraná, Brasil

E-mail: mopiffer@yahoo.com.br

\section{Resumo}

O objetivo desta pesquisa foi realizar uma análise bibliométrica e identificar as técnicas qualitativas utilizadas nas pesquisas sobre pobreza no período de 2015 a 03 de março de 2020, além de discutir as principais vantagens e desvantagens associadas a essas técnicas. Para tanto, foi utilizada a base de dados SCOPUS da qual foram identificados os estudos mais relevantes, os periódicos que mais publicaram sobre o assunto, e construído um quadro com os objetivos e técnicas qualitativas utilizadas pelos autores, a partir de 43 artigos científicos, publicados em 38 periódicos e escritos por 121 autores e co-autores. Constatou-se que as pesquisas qualitativas sobre o tema da pobreza distinguem-se de acordo com o público e a localidade alvo, não havendo um padrão de técnicas utilizadas, as quais dependerão dos problemas e objetivos da pesquisa, porém algumas técnicas foram mais comumente utilizadas como observação em campo, observação participante, entrevistas em profundidade, grupo focal, análise de conteúdo e análise temática. As técnicas qualitativas possibilitaram aos pesquisadores o entendimento em profundidade das experiências e comportamentos dos grupos investigados, a 
identificação de constructos emergentes e a (re)construção de suas percepções sobre os objetos/problemas de pesquisa, contribuindo para a apreensão das causas e efeitos da pobreza em toda a sua complexidade. A impossibilidade de generalização dos resultados, a necessidade de investigações longitudinais que exigem grande dispêndio de tempo e recursos financeiros, a impossibilidade de conhecer a amostra, a veracidade das informações e de captação de narrativas não verbais nas pesquisas em mídias sociais foram algumas limitações identificadas.

Palavras-chave: Pesquisa bibliométrica; Pesquisa qualitativa; Pobreza.

\section{Abstract}

The objective of this research was to carry out a bibliometric analysis and identify the qualitative techniques used in the research on poverty in the period from 2015 to March 3, 2020, in addition to discussing the main advantages and disadvantages associated with these techniques. For this, the SCOPUS database was used, from which the most relevant studies were identified, the journals that most published on the subject, and a table was constructed with the objectives and qualitative techniques used by the authors, from 43 scientific articles, published in 38 journals and written by 121 authors and co-authors. It was found that qualitative research on the theme of poverty is distinguished according to the audience and the target location, with no standard of techniques used, which will depend on the problems and objectives of the research, however some techniques were more commonly used such as field observation, participant observation, in-depth interviews, focus group, content analysis and thematic analysis. Qualitative techniques enabled researchers to understand in depth the experiences and behaviors of the investigated groups, the identification of emerging constructs and the (re) construction of their perceptions about research objects / problems, contributing to the apprehension of the causes and effects of poverty. in all its complexity. Some limitations identified were the impossibility of generalizing the results, the need for longitudinal investigations that require a large expenditure of time and financial resources, the impossibility of knowing the sample, the veracity of information and the capture of non-verbal narratives in social media research.

Keywords: Bibliometric research; Qualitative research; Poverty.

\section{Resumen}

El objetivo de esta investigación fue realizar un análisis bibliométrico e identificar las técnicas cualitativas utilizadas en las investigaciones sobre la pobreza a partir del año 2015, además de examinar las principales ventajas y desventajas asociadas a esas técnicas. Para eso, fue utilizada la base de datos SCOPUS de la cual se identificaron los estudios más relevantes, las revistas que más publicaron sobre el tema, y se construyó un cuadro con los objetivos y técnicas cualitativas utilizadas por los autores a partir de 43 artículos científicos, publicados en 38 revistas y escritos por 121 autores y coautores. Se constató que la investigación cualitativa sobre el tema pobreza se diferencia según el 
público y el lugar objetivos, y no existe un estándar de las técnicas utilizadas, que dependerá de los problemas y objetivos de la investigación, pero algunas técnicas se utilizaron más comúnmente como la observación en el campo, observación participante, entrevistas a fondo, grupo focal, análisis de contenido y el análisis temático. Las técnicas cualitativas permitieron a los investigadores comprender en profundidad las experiencias y los comportamientos de los grupos investigados, identificar las construcciones emergentes y (re)construir sus percepciones sobre los objetos/problemas de la investigación, contribuyendo a la comprensión de las causas y los efectos de la pobreza en toda su complejidad. La imposibilidad de generalización de los resultados, la necesidad de investigaciones longitudinales que requieren mucho tiempo y recursos financieros, la imposibilidad de conocer la muestra, la veracidad de la información y la captura de narraciones no verbales en la investigación en los medios sociales fueron algunas de las limitaciones identificadas.

Palabras clave: Investigación bibliométrica; Investigación cualitativa; Pobreza.

\section{Introdução}

Os estudos sobre pobreza surgem a partir da reconstrução do Pós-2 ${ }^{\mathrm{a}}$ Guerra Mundial, a princípio fazendo uso de medidas baseadas na renda. Contudo, tal abordagem tornou-se insuficiente para medir a pobreza como um fenômeno complexo, não restrito à insuficiência de renda, passando-se a compreendê-la como um problema multidimensional. Alinhada à complexidade do fenômeno da pobreza, emergiram diversas abordagens teóricas para o entendimento acadêmico da temática, entre elas a abordagem da pobreza absoluta (monetária ou unidimensional), da pobreza relativa, da pobreza subjetiva, das necessidades básicas e das capacitações básicas seniana (Kageyama \& Hoffmann, 2006; Rocha, 2006; Silva, Lacerda, \& Neder, 2011).

Apesar das diversas abordagens teóricas sobre a pobreza, não foi o intuito desta pesquisa adotar ou discutir os conceitos, tampouco adotar alguns deles como critérios de busca da literatura, mas se ater às abordagens metodológicas qualitativas que estão sendo utilizadas pelos estudos mais recentes sobre a temática pobreza.

Tradicionalmente os estudos empíricos sobre a pobreza utilizam abordagens quantitativas de pesquisa, por essa razão não conseguem captar e analisar dimensões sociais subjetivas importantes que permeiam esse problema social complexo, conhecimento que poderia ser utilizado para o delineamento de políticas públicas e projetos mais efetivos em termos de alívio da pobreza, promoção do desenvolvimento socioeconômico e bem-estar social. A abordagem qualitativa se atém ao estudo dos fenômenos sociais em sua complexidade e no posicionamento dos indivíduos e atores sobre esses fenômenos, se 
pautando por uma análise aprofundada que consegue captar dimensões subjetivas, latentes, constructos e temáticas emergentes, além de permitir a reflexividade do pesquisador ao longo do processo de pesquisa (Alexander et al., 2017a; Zamora-Sarabia, Guterman, Sanz-Barbero, Rico Gómez, \& Otero García, 2019; Franz \& Cook, 2020).

Há, portanto, uma lacuna no conhecimento científico sobre a temática com a qual este estudo pretende contribuir. Nesse sentido, cumpre saber qual o espaço ocupado pelas abordagens/métodos qualitativos nas pesquisas recentes sobre pobreza. Com esse intuito, o objetivo desta pesquisa é realizar uma análise bibliométrica e identificar as técnicas qualitativas utilizadas nas pesquisas sobre pobreza publicadas no período de 2015 a 03 de março de 2020, além de discutir as principais vantagens e desvantagens associadas a essas técnicas. Para tanto, selecionou-se somente as pesquisas em que a avaliação da situação de pobreza ou de algum programa ou projeto específico para alívio da pobreza foi o foco principal dos estudos, apesar da transversalidade e complexidade que permeia a temática.

\section{Metodologia}

A Revisão Sistemática de Literatura (RSL) foi conduzida a partir do protocolo de pesquisa PRISMA (Moher et al., 2012) guiada pelas questões definidas de acordo com o conhecimento prévio dos pesquisadores sobre o tema. Dessa forma, inicialmente foi construída uma string de busca a partir da inclusão de termos relacionados ao tema de pesquisa.

A versão final da string de busca construída para a base de periódicos Scopus é apresentada na Tabela 1, assim como a quantidade de resultados em termos do número de publicações. A base foi utilizada em razão de apresentar os dados dispostos no formato necessário para a realização de análise bibliométrica no aplicativo Bibliometrix. Três critérios de inclusão foram considerados nesse estudo: apenas artigos publicados em periódicos, artigos publicados na língua inglesa a fim de captar o que há de mais recente na literatura internacional sobre a temática, e artigos publicados no período compreendido entre o ano 2015 e 03 de março de 2020 na área de Ciências Sociais. A escolha da área de Ciências Sociais foi um critério prévio adotado para selecionar pesquisas em que a avaliação da pobreza ou de algum programa ou projeto específico para alívio da pobreza foi o foco principal dos estudos. Os estudos sobre pobreza se difundiram no pós-2 $2^{\text {a }}$ Guerra Mundial no escopo das Ciências Sociais e Ciências Sociais Aplicadas por ser esse um fenômeno social, apesar da transversalidade e complexidade que permeia a temática (Rocha, 2006). 
Tabela 1 - String de busca dos artigos do portfólio

\begin{tabular}{c|c|c}
\hline \multicolumn{1}{c|}{ Base de } & String de busca & Result \\
Dados & \multicolumn{1}{|c|}{ TITLE-ABS-KEY("poverty") AND “qualitative } & 423 \\
\hline Scopus & $\begin{array}{l}\text { design" OR "qualitative research" OR "qualitative } \\
\text { methods" OR "qualitative exploration") }\end{array}$ & \\
\hline
\end{tabular}

Fonte: Resultados da pesquisa (2020).

$\mathrm{Na}$ primeira etapa dessa pesquisa a string de busca foi estabelecida no intuito de construir o conhecimento sobre o tema "pobreza e pesquisa qualitativa", além disso identificar as principais características desse conjunto de publicações.

Foram encontrados 423 artigos. Após a leitura dos títulos e resumos, foram removidos do banco de artigos 5 publicações por falta de acesso e 375 publicações devido aos seus respectivos objetivos de pesquisa não consistirem na avaliação da pobreza ou de algum programa ou projeto específico para alívio da pobreza, restando um banco com total de 43 publicações a serem analisadas de acordo com os critérios estabelecidos nesta pesquisa. Os termos utilizados para busca na base de dados foram "poverty" combinado com "qualitative desing", "qualitative research", "qualitative methods" e "qualitative exploration" sendo a busca aplicada no título, resumo e palavras-chave.

O protocolo de pesquisa foi construído a partir da taxonomia de classificação, composto pelas seguintes etapas: (i) identificação do problema de pesquisa; (ii) a busca nas bases em conjunto com os critérios de inclusão; (iii) a remoção de artigos sem acesso integral; (iv) a leitura do título, resumo e dos artigos a fim de identificar o alinhamento do estudo com as questões de pesquisa e temática definida; (v) análise detalhada das características do portfólio de pesquisa; (vi) por fim, a análise de termos visando identificar as abordagens e direcionamentos das pesquisas.

A análise da RSL foi conduzida em três etapas: (i) a classificação detalhada do portfólio de pesquisa, incluindo a identificação dos principais periódicos que vinculam pesquisas da temática abordada, análise da evolução temporal da frequência de publicação, a identificação dos artigos mais relevantes do portfólio de acordo com o número de citações e a identificação dos países relacionados às publicações; (ii) a análise de coocorrência de termos textuais a partir da frequência de termos objetivando identificar o direcionamento dos estudos (iii) por fim, realizou-se a construção de um framework teórico a partir da identificação das abordagens propostas nos estudos do portfólio. As análises dos documentos selecionados foram realizadas no aplicativo Biblioshiny, que faz parte do pacote Bibliometrix 2.1.2 (Aria \& 
Cuccurullo, 2017), desenvolvido para ser utilizado em linguagem de programação R 3.5.2 (R Core Team, 2019).

Na primeira etapa (i) da RSL buscou-se responder os seguintes questionamentos de pesquisa: Qual a frequência anual das publicações? Quais os estudos mais citados do portfólio de pesquisa analisado? Quais periódicos vinculam pesquisas qualitativas sobre o tema pobreza? Também compôs a primeira etapa a utilização do indicador bibliométrico quantidade de citações com o objetivo de avaliar a estrutura de citações recebidas por autores e coautores componentes do corpus textual, pois demonstram uma medida de influência, já que os pesquisadores citam os documentos que consideram importantes.

Na etapa (ii) da RSL foram construídas nuvens de palavras a partir dos termos mais frequentes extraídos dos abstracts, das palavras-chave (keywords) atribuídas pelos autores e dos títulos dos artigos. A nuvem de palavras refere-se à organização e ao agrupamento de um conjunto de palavras em função da sua ocorrência, o que possibilita a identificação do conteúdo lexical e da centralidade representacional do portfólio bibliográfico. Por fim, na etapa (iii) da RSL foi construído um quadro resumo com os objetivos e técnicas de pesquisa utilizadas pelos 43 estudos do portfólio.

\section{Resultados e Discussão}

Nesta seção são apresentados os resultados dessa pesquisa, demonstrando três análises bibliométricas, a produtividade de autores, a produtividade dos periódicos e a frequência de ocorrência e coocorrência de palavras e as abordagens/métodos qualitativos utilizados pelos autores.

A seguir tem-se a análise descritiva do portfólio que se refere aos indicadores relacionados à citação e ao conteúdo dos 43 artigos selecionados. Assim, avalia-se a quantidade de artigos publicados ao longo do tempo, a distribuição geográfica dos autores e coautores e a composição de autoria nos trabalhos do portfólio textual.

Observa-se na Figura 1 a evolução temporal da frequência de publicações apresentada por todos os autores e coautores componentes do portfólio textual. Com base nos 43 artigos analisados nessa pesquisa, evidencia-se que o maior número de publicações ocorreu no ano de 2019, com um total de 16 documentos (Figura 1). 
Figura 1 - Evolução temporal das publicações do portfólio

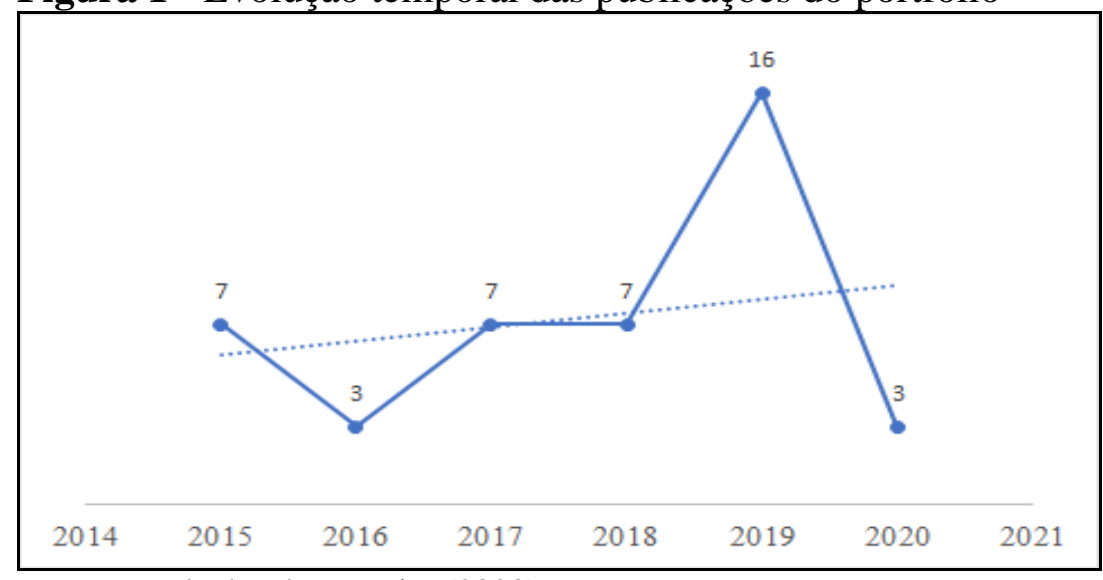

Fonte: Resultados da pesquisa (2020).

A média de citações referente aos 43 artigos do portfólio em todo período de análise foi de aproximadamente 1,72 citações por documento publicado, divididos entre 121 autores e coautores. Também foi identificada a média de 2,81 autores e coautores por documento. Para analisar a cooperação entre os autores das publicações com coautorias, foi identificado o Índice de Colaboração (Elango \& Rajendran, 2014; Koseoglu, 2016): observou-se que o número médio de autores por trabalho em conjunto foi de 3,17 , denotando que em média pouco mais de 3 autores assinaram os artigos publicados conjuntamente.

No Quadro 1 são apresentadas as informações referentes ao número de citações das 23 publicações que foram citadas, componentes do corpus textual da presente pesquisa, em ordem do mais citado ao menos citado. As outras 20 publicações do portfólio não foram citadas na base Scopus e, por essa razão, não apresentadas no Quadro 1. As publicações de 2020 também não apresentaram citações, razão pela qual o Quadro 1 contempla somente as publicações do período de 2015 a 2019. O cálculo da média anual de citações foi realizado pelo quociente entre o número de citações e a quantidade de tempo (em anos) decorrido da data de publicação.

Quadro 1 - Número total e média de citações por ano dos 23 artigos do portfólio publicados entre 2015 e 2019 que foram citados na base Scopus

\begin{tabular}{|l|c|c|}
\hline Autores & $\begin{array}{c}\text { Média de } \\
\text { Cotal de } \\
\text { Citações }\end{array}$ & $\begin{array}{c}\text { Citações por } \\
\text { Ano }\end{array}$ \\
\hline Morrow \& Crivello (2015) & 13 & 2,6 \\
Thompson, Smith \& Cummins (2018) & 8 & 4 \\
Ioris (2016) & 8 & 2 \\
Fahmy, Sutton \& Pemberton (2015) & 7 & 1,4 \\
et al. (2017) & 5 & 1,67 \\
Dube, Mtapuri \& Matunhu (2018) & 4 & 2 \\
Kulb et al. (2016) & 4 & 3 \\
Andresen \& Meiland (2019) & 3 & 1 \\
Caplan, Purser \& Kindle (2017) & 3 & 2
\end{tabular}


Fenwick (2017)

Anaafo \& Guba (2017)

Sripanich, Nitivattananon \& Perera (2015)

Jahan et al. (2015)

Rose \& Mcauley (2019)

Kabir \& Louise Maitrot (2019)

$\mathrm{Xu}$ et al. (2018)

Hamenoo, Dwomoh \& Gyeke (2018)

Turner \& Juntune (2018)

Alexander et al. (2017)

Strier et al. (2016)

Ceresola (2015)

Simpson, Lumsden \& Clark (2015)

Fonte: Resultados da pesquisa (2020).

Entre os mais citados foram identificados 3 estudos metodológicos: Morrow e Crivello (2015) suscitaram a importância da pesquisa qualitativa longitudinal com crianças e jovens nos estudos internacionais sobre desenvolvimento econômico; Fahmy, Sutton \& Pemberton (2015) avaliaram a opinião pública sobre aspectos qualitativos na medição da pobreza; Kulb et al. (2016) avaliaram a contribuição dos censos qualitativos em informar políticas de alívio da pobreza, sobretudo nas pequenas cidades e comunidades rurais nos Estados Unidos.

Alguns estudos analisaram a contribuição de programas ou projetos voltados ao alívio da pobreza do ponto de vista dos atores envolvidos/beneficiários: o microcrédito ou fundos de financiamento comunitário na Tailândia (Sripanich, Nitivattananon \& Perera, 2015; Ali et al., 2017) e no empoderamento feminino no Quênia (Kulb et al., 2016); reformas agrárias em Gana (Anaafo \& Guba, 2017); programas de redução da pobreza no Bangladesh (Kabir \& Louise Maitrot, 2019).

Ainda entre os mais citados, Thompson, Smith \& Cummins (2018) analisaram os desafios à saúde e bem-estar da pobreza alimentar em Londres. Ioris (2016) a persistência da pobreza na região Amazônica brasileira e boliviana. Foi identificada uma gama de estudos focados na avaliação da situação de pobreza por parte de crianças (Hamenoo, Dwomoh \& Gyeke, 2018; Andresen \& Meiland, 2019; Fattore \& Fegter, 2019) e de pós-graduandos que experimentaram a pobreza na infância (Turner \& Juntune, 2018), como também por parte das mulheres (Kulb et al., 2016; Xu et al., 2018).

Na Tabela 2 verifica-se o número de artigos publicados em cada um dos periódicos do portfólio bibliográfico. Pode-se observar que o periódico Children and Youth Services Review apresenta o maior número de artigos, com total de 4 publicações. Enquanto os periódicos Health and Social Care in The Community e Social Science and Medicine 
apresentam 2 publicações. Os demais periódicos, contabilizando 35, apresentaram apenas uma publicação.

Tabela 2 - Número de publicações por periódicos

\begin{tabular}{|c|c|}
\hline Periódicos & $\begin{array}{l}\text { Número de } \\
\text { Publicações }\end{array}$ \\
\hline Children and Youth Services Review & 4 \\
\hline Health and Social Care in The Community & 2 \\
\hline Social Science and Medicine & 2 \\
\hline African Journal of Science, Technology, Innovation and Development & 1 \\
\hline Annals of The American Academy of Political and Social Science & 1 \\
\hline Asian Social Science & 1 \\
\hline Asian Social Work and Policy Review & 1 \\
\hline Canadian Journal of African Studies & 1 \\
\hline Cogent Social Sciences & 1 \\
\hline Community Development & 1 \\
\hline Culture, Health and Sexuality & 1 \\
\hline Development in Practice & 1 \\
\hline Development Policy Review & 1 \\
\hline Geographical Journal & 1 \\
\hline Habitat International & 1 \\
\hline Humanities and Social Sciences Reviews & 1 \\
\hline Ids Bulletin & 1 \\
\hline International Journal of Scientific and Technology Research & 1 \\
\hline International Journal of Social Research Methodology & 1 \\
\hline International Journal of Sociology and Social Policy & 1 \\
\hline International Social Work & 1 \\
\hline Jamba: Journal of Disaster Risk Studies & 1 \\
\hline Journal of Advanced Academics & 1 \\
\hline Journal of China Tourism Research & 1 \\
\hline Journal of Evidence-Informed Social Work & 1 \\
\hline Journal of Human Ecology & 1 \\
\hline Journal of International Development & 1 \\
\hline Journal of Rural Studies & 1 \\
\hline Journal of Social Policy & 1 \\
\hline Journal of Social Sciences & 1 \\
\hline Journal of Social Work & 1 \\
\hline Journal of Youth Studies & 1 \\
\hline Men and Masculinities & 1 \\
\hline Qualitative Social Work & 1 \\
\hline Qualitative Sociology Review & 1 \\
\hline Social and Cultural Geography & 1 \\
\hline Sociological Forum & 1 \\
\hline Voluntas & 1 \\
\hline
\end{tabular}

Fonte: Resultados da pesquisa (2020).

No rol de periódicos (Tabela 2) figuraram os pertencentes a diversas áreas do conhecimento tangentes à temática da pobreza, como da Sociologia, Ciência Política, Geografia, Turismo, além dos especializados em temáticas relacionadas à pobreza como o desenvolvimento socioeconômico, ciência, tecnologia e inovação, estudos rurais. Também figuraram os periódicos da área das Ciências da Saúde e os focados na relação dessa área com as temáticas das Ciências Sociais, a exemplo do Social Science and Medicine e do Culture, Health and Sexuality. Esse levantamento denota a complexidade e transversalidade inerente à 
temática da pobreza, nas suas mais variadas facetas e sob as percepções de diferentes grupos que vivenciam o problema.

Nas Figuras 2, 3 e 4 são apresentados os 50 termos mais frequentes extraídos dos abstracts, das palavras-chave (keywords) atribuídas pelos autores e dos títulos dos 43 artigos do corpus analisado, respectivamente, categorizadas de acordo com o objetivo do estudo, a metodologia aplicada e os resultados encontrados, sendo construídas com base na matriz de incidência de palavras, em que o tamanho dos termos é proporcional a sua ocorrência.

$\mathrm{Na}$ análise do conteúdo dos abstracts (Figura 2) dos 43 artigos que compõem esse portfólio observa-se que os dez termos mais frequentes foram poverty (153 vezes), social (54 vezes), study (54 vezes), development (45 vezes), qualitative (44 vezes), poor (38 vezes), children (30 vezes), rural (29 vezes), data (28 vezes) e community (25 vezes).

Figura 2 - Nuvem de palavras dos abstracts dos 43 artigos do portfólio

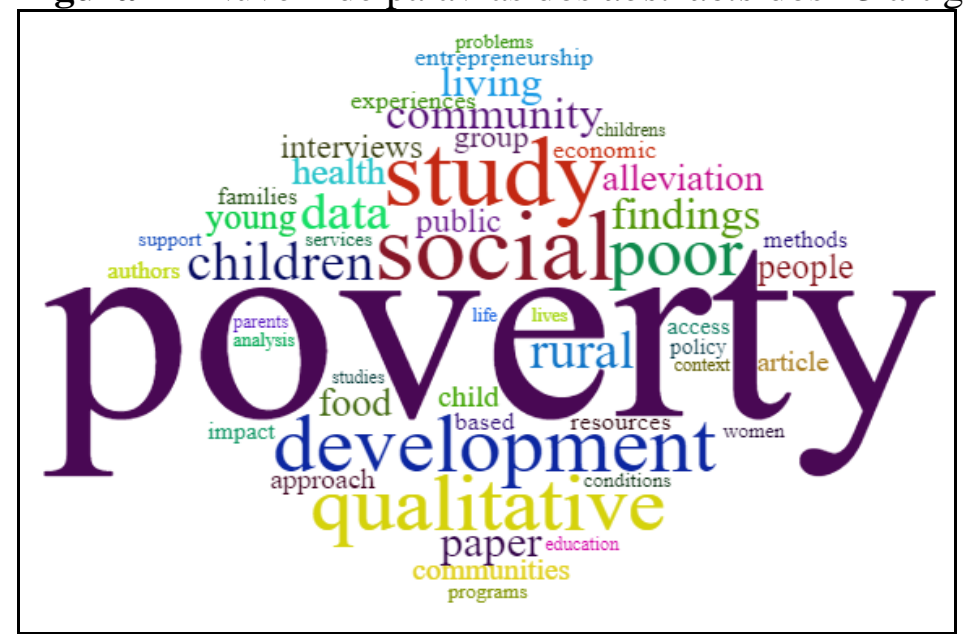

Fonte: Resultados da pesquisa (2020).

Nas palavras-chave atribuídas pelos autores (Figura 3) para identificação dos 43 artigos que compõem esse portfólio, observou-se que os dez termos mais frequentes foram poverty (18 vezes), qualitative research (6 vezes), gender (4 vezes), poverty reduction (4 vezes), education (3 vezes), social policy (3 vezes), bangladesh (2 vezes), brazil (2 vezes), child poverty (2 vezes) e children (2 vezes). 
Figura 3 - Nuvem de palavras das palavras-chave dos autores dos 43 artigos do portfólio

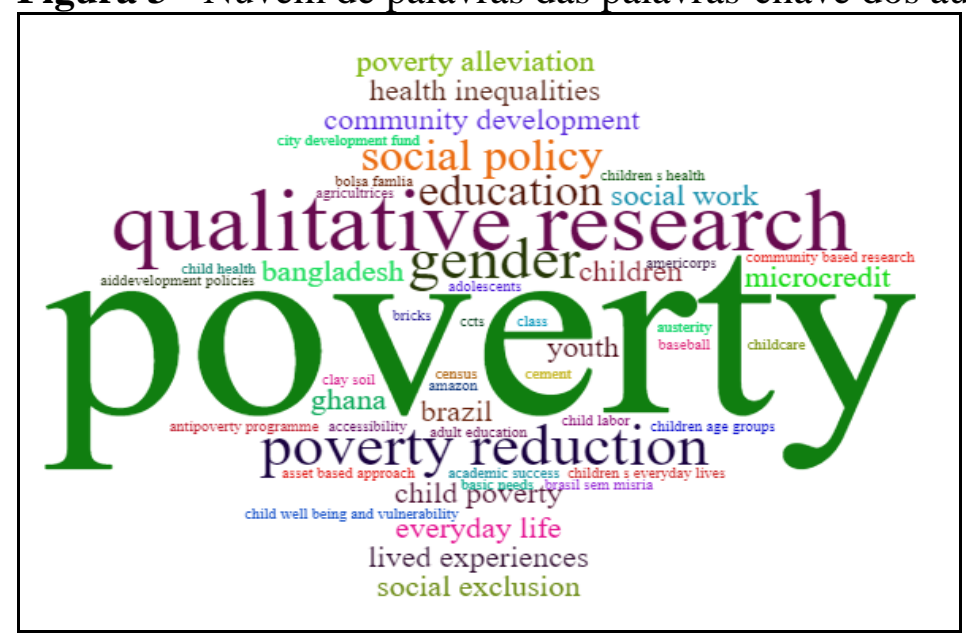

Fonte: Resultados da pesquisa (2020).

Nas palavras constituintes dos títulos (Figura 4) dos 43 artigos que compõem esse portfólio observou-se que os dez termos mais frequentes foram poverty (26 vezes), qualitative (10 vezes), social (10 vezes), study (8 vezes), development (7 vezes), rural (7 vezes), child (5 vezes), health (5 vezes), poor (5 vezes) e alleviation (4 vezes).

Figura 4 - Nuvem de palavras dos títulos dos 43 artigos do portfólio

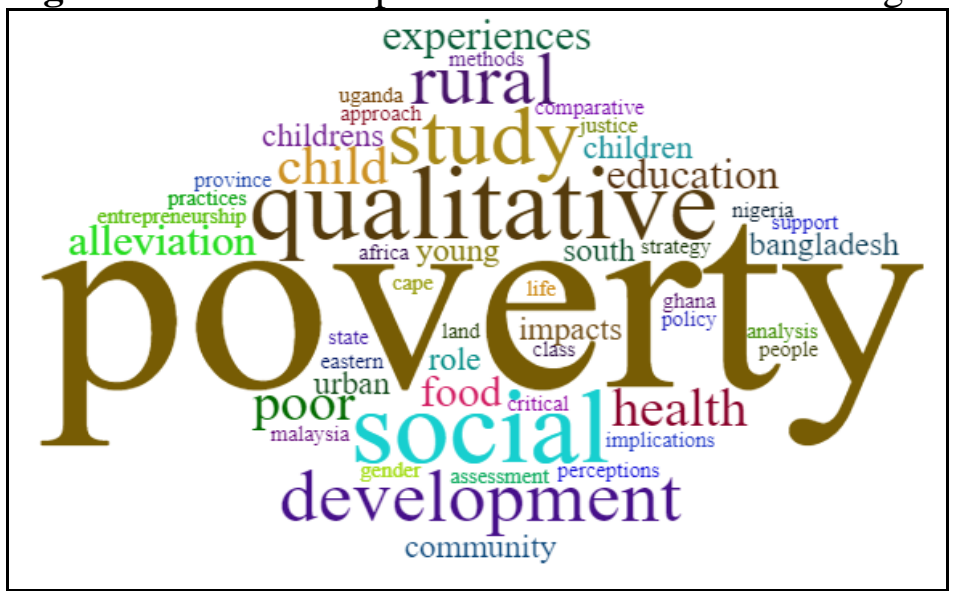

Fonte: Resultados da pesquisa (2020).

A análise geral da nuvem de palavras constantes nos abstracts, palavras-chave e títulos dos artigos do portfólio revelaram alguns assuntos e temáticas recorrentes nas pesquisas qualitativas sobre pobreza, tais como questões de gênero, estudos em localidades e grupos específicos e em comunidades rurais, pobreza infantil e jovem, aspectos relacionados à saúde e educação, termos remetentes a técnicas de pesquisa qualitativa, estratégias e programas de alívio da pobreza e promoção do desenvolvimento, além do grande número de estudos sobre países do continente Africano e Asiático. Considera-se que esse grupo de publicações está alinhado aos objetivos da presente pesquisa, dada a análise dos termos presentes nos resumos, palavras-chave e títulos das publicações. 
Esses achados fornecem um perfil dos estudos internacionais sobre pobreza com abordagens qualitativas: deram voz a grupos específicos vulneráveis, a exemplo de crianças, jovens, mulheres e idosos, que vivenciam ou vivenciaram a pobreza durante uma fase de suas vidas e as implicações negativas dessa condição em termos de educação, saúde, condições de trabalho e geração de renda, além de aspectos subjetivos como o contexto vivencial, cultural, crenças e valores e as influências psicológicas; predominância de estudos em localidades rurais e nos continentes Africano e Asiático; avaliação da efetividade de programas e projetos de direcionados a grupos específicos e proposição de estratégias de alívio da pobreza delineadas a partir das necessidades desses grupos.

Em 2015 mais de $85 \%$ do contingente mundial de extremamente pobres ${ }^{1}$ viviam na África Subsaariana e no Sul da Ásia (mais de 651 milhões de pessoas). Em 2013, essas regiões abrigaram $65,4 \%$ e $17,7 \%$, respectivamente, do contingente mundial de multidimensionalmente pobres $^{2}$. A incidência da pobreza tende a ser maior entre crianças e mulheres, especialmente nessas duas regiões mundiais, haja vista que durante o período reprodutivo de 25 a 54 anos, globalmente cerca de $86 \%$ das mulheres fica fora da força de trabalho (agravado se possuir filhos jovens) e 60\% é sub-remunerada, além de apenas 19\% delas exercerem atividades autônomas contra 40\% dos homens (The World Bank, 2018).

Os resultados desta RSL estão alinhados a esse perfil mundial da pobreza. Entre os países alvo dos estudos, figuraram África do Sul, Nigéria, Congo, Quênia, Gana, Nigéria, Uganda, Zimbábue (da África Subsaariana) e Malásia, Indonésia, Tailândia e Bangladesh (do Sul da Ásia), estudos em comunidades rurais, com grupos vulneráveis de crianças, jovens e mulheres. Outra constatação é a de que a situação de pobreza pode ser agravada por guerras, conflitos políticos, corrupção e desastres naturais (The World Bank, 2018), esta última investigada pelo estudo da relação das enchentes com a pobreza de uma comunidade rural no Zimbábue (Dube et al. 2018).

No Quadro 2 é apresentado o portfólio das publicações selecionadas, de acordo com os critérios estabelecidos nessa pesquisa. Foram analisados 43 artigos científicos, escritos por 121 autores e coautores, distribuídos em 38 periódicos, no período de 2015 a 03 de março de 2020.

\footnotetext{
${ }^{1} \mathrm{O}$ Banco Mundial classifica como extremamente pobres os que vivem com menos de 1,90 dólares norteamericanos (US\$) por dia (à Paridade do Poder de Compra de 2011) (THE WORLD BANK, 2018).

2 O Banco Mundial contemplou 3 dimensões na construção do índice de pobreza multidimensional (monetária, educação e infraestrutura básica), compostas por 6 sub-dimensões: monetária, grau de escolaridade, matrículas escolares, eletricidade, condições sanitárias e água potável (THE WORLD BANK, 2018).
} 
A partir da leitura e análise dos documentos que compõem o portfólio apresentado no Quadro 2 foi possibilitado tecer algumas considerações sobre o uso de abordagens qualitativas para o estudo da temática pobreza. As pesquisas com abordagens qualitativas para avaliação da pobreza ou de algum projeto de alívio da pobreza distinguem-se de acordo com o público e a localidade alvo do estudo, não havendo um consenso a respeito de um padrão de técnicas utilizadas, as quais dependerão dos problemas e objetivos da pesquisa. Porém, foram identificadas algumas técnicas de pesquisa mais comumente utilizadas no campo da pesquisa qualitativa como observação em campo, observação participante, questionários, entrevistas em profundidade (individual ou coletivas), estudo de caso, grupo focal, análise de conteúdo, análise temática, pesquisas documental, fenomenológica, bibliográfica e etnográfica. Observou-se também o uso das técnicas da análise de fotografias (García \& Ritterbusch, 2015; Anaafo \& Guba, 2017), Photovoice 3 (Sarti, Dedding, \& Bunders, 2019), análise de mídia (Fenwick, 2017) e de postagens em rede social (Caplan, Purser, \& Kindle, 2017).

É mister observar que, na maioria das pesquisas, foram utilizadas mais de uma técnica de pesquisa qualitativa para atender os respetivos objetivos. Esse pluralismo metodológico advém de uma necessidade metodológica de cobertura adequada dos acontecimentos sociais. A investigação empírica exige a observação sistemática dos acontecimentos, inferir os sentidos deles a partir das opiniões dos atores e expectadores; técnicas de entrevista e interpretação dos vestígios materiais deixados pelos atores e expectadores; uma análise sistemática (Bauer, Gaskell, \& Allum, 2015; Tuzzo \& Braga, 2016).

Os principais argumentos dos pesquisadores de pobreza a favor da utilização das técnicas qualitativas foram captar detalhadamente a percepção das experiências dos participantes estudados, bem como identificar temáticas ou constructos emergentes que contribuem para compreensão em profundidade das causas e efeitos da pobreza em toda a sua complexidade, para a proposição de projetos de alívio da pobreza ou aperfeiçoamento dos já existentes, além de suscitar questões para pesquisas futuras (Alexander et al., 2017; ZamoraSarabia et al., 2019; Franz \& Cook, 2020).

Outro aspecto importante abordado nesses estudos está relacionado ao processo de amostragem. Foi observado que ao estabelecer uma abordagem qualitativa o pesquisador deve ter cuidados a fim de validar os resultados da pesquisa, e independente do processo de

\footnotetext{
3 Técnica na qual as crianças que cresceram em contexto de pobreza tiraram fotos de coisas e locais do seu ambiente local que consideraram importantes (Sarti, Dedding \& Bunders, 2019).
} 
amostragem utilizado ser probabilístico ou não, a população de indivíduos ou grupos analisados deve representar a diversidade da realidade alvo do estudo.

A impossibilidade de generalização dos resultados é uma das fragilidades da pesquisa qualitativa, cujos resultados são válidos somente para o contexto e grupos em que a pesquisa ocorreu, apesar de o delineamento da pesquisa poder auxiliar outras pesquisas semelhantes (Zamora-Sarabia et al., 2019; Inglis, McHardy, Sosu, McAteer, \& Biggs, 2019). Outra desvantagem é a necessidade de investigações longitudinais para apreensão das complexidades dinâmicas dos processos e práticas de vida a partir da percepção dos atores, das suas estratégias para a superação dos problemas relacionados à pobreza e suas trajetórias de mudança de vida, o que exige grande dispêndio de tempo e recursos financeiros para o desenvolvimento da pesquisa (Morrow \& Crivello, 2015; Sarti et al., 2019).

As pesquisas qualitativas sobre pobreza baseadas em análises de conteúdo em mídias sociais ou outros recursos virtuais possuem alguns entraves, tais como a impossibilidade de conhecer e descrever a amostra de respondentes, de verificar empiricamente se as declarações das pessoas sobre sua condição de pobreza são verdadeiras, vieses de seleção e informação, relatos retrospectivos e contágios emocionais e a impossibilidade de captar narrativas sutis, não verbais ou veladas, que estão presentes em conversas presenciais e interativas, a exemplo das ocorridas nos grupos focais (Caplan et al., 2017). Outra desvantagem consiste em captar a opinião dos participantes sobre o que viram ao seu redor e não necessariamente sobre o que experimentaram em suas vidas, como pode ocorrer em entrevistas coletivas e grupos focais (Ninsiima et al., 2020), além do viés das observações realizadas pelos pesquisadores que dependem do contexto de vida onde cresceram e do mundo social que estudam (Kabuye \& Mukasa, 2018; Korstjens \& Moser, 2018).

O que se busca nas pesquisas qualitativas é a compreensão dos fenômenos atrelados aos indivíduos em estudo em relação a sua dimensão sociocultural representada por meio de crenças, valores, opiniões, representações, formas de relação, simbologias, usos, costumes, comportamentos e práticas. No entanto, os estudos qualitativos devem possuir seu caráter científico ao estabelecer parâmetros e normas que lhe garantam a confiabilidade e validade dos resultados. Dessa maneira, o pesquisador qualitativo deve elaborar instrumentos que identifiquem todas as dimensões da situação a ser investigada. Portanto, uma amostra qualitativa válida é a que retrata, em quantidade e intensidade, as diversas dimensões de determinado fenômeno e representa a qualidade das atuações e relações em todo decorrer do processo (Minayo, 2017). 
Observou-se que nas investigações qualitativas o indivíduo ou grupo objeto de estudo deve ser o elemento fundamental que guiará o pesquisador nas suas escolhas desde o delineamento da pesquisa, os métodos de coleta de dados, as técnicas de análise e interpretação até a elaboração do seu relatório de pesquisa. Ao realizar o processo de triangulação de dados em uma pesquisa qualitativa o pesquisador terá a possibilidade de gerar novas questões de pesquisa, consequentemente tem a oportunidade de produzir novas pesquisas qualitativas ou quantitativas ou mesmo uma nova triangulação. Dessa forma, o pesquisador tem condições de antecipar as necessidades de diferentes recortes e ângulos da pesquisa no intuito de não ficar limitado ou restrito a uma única perspectiva (Tuzzo \& Braga, 2016).

Foi possível observar nos estudos do portfólio, selecionados nesta pesquisa, que o uso de abordagens qualitativas sobre a temática pobreza também deve propiciar que o pesquisador esteja atento às mudanças na direção da pesquisa, de forma a refletir sobre a sua jornada como uma atividade interativa, ou seja, a reflexividade ocorre simultaneamente conforme a pesquisa avança. O pesquisador, assim, é moldado durante o processo de pesquisa pois também faz parte do mundo social que estuda. Portanto, faz-se necessário que reconheça e examine seus antecedentes sociais que possam influenciar na prática da pesquisa (Korstjens \& Moser, 2018).

Quadro 2 - Portfólio de artigos que compõem o corpus de pesquisa, objetivos e técnicas de pesquisa utilizadas

\begin{tabular}{|c|c|c|}
\hline Autores & Objetivo & Técnicas de Pesquisa \\
\hline $\begin{array}{c}\text { (Franz \& } \\
\text { Cook, 2020) }\end{array}$ & $\begin{array}{l}\text { Descrever as perspectivas dos stakeholders envolvidos } \\
\text { com a organização missionária baseada na fé para } \\
\text { discernir os componentes e a eficácia dos esforços para } \\
\text { apoiar o crescimento dos estudantes dentro e além das } \\
\text { habilidades atléticas na República Dominicana. }\end{array}$ & $\begin{array}{l}\text { Grupo Focal com (treinadores, pais, } \\
\text { líderes comunitários) } \\
\text { Entrevistas individuais com lideranças } \\
\text { Estudo de caso instrumental }\end{array}$ \\
\hline $\begin{array}{l}\text { (MacDonald } \\
\text { et al., 2020) }\end{array}$ & $\begin{array}{l}\text { Investigar como os problemas dos jovens da classe } \\
\text { trabalhadora no Reino Unido são, muitas vezes, o } \\
\text { resultado das desigualdades nas oportunidades de } \\
\text { emprego entre as gerações. }\end{array}$ & $\begin{array}{l}\text { Entrevistas com } 20 \text { famílias vivendo } \\
\text { em bairros extremamente pobres. }\end{array}$ \\
\hline $\begin{array}{l}\text { (Ninsiima et } \\
\text { al., 2020) }\end{array}$ & $\begin{array}{l}\text { Mostrar como a pobreza interage com as relações de } \\
\text { poder de gênero para ter impacto na vida sexual e } \\
\text { reprodutiva de meninas adolescentes em } 6 \text { escolas no } \\
\text { Oeste de Uganda. }\end{array}$ & $\begin{array}{l}\text { Entrevistas em profundidade (59) com } \\
\text { mulheres e homens jovens de 12-14 } \\
\text { anos, professores, trabalhadores da } \\
\text { saúde, polícia, agentes de } \\
\text { desenvolvimento comunitário e } \\
\text { funcionários distritais. Grupos focais } \\
\text { (11): } 4 \text { com jovens de } 12-14 \text { anos, } 4 \\
\text { com professores e } 3 \text { com pais. }\end{array}$ \\
\hline $\begin{array}{l}\text { (Sewell et al., } \\
\text { 2019) }\end{array}$ & $\begin{array}{l}\text { Investigar e comparar as percepções das comunidades } \\
\text { rurais sobre o papel das estradas como uma estratégia de } \\
\text { alívio da pobreza em } 2 \text { comunidades rurais da África do } \\
\text { Sul. }\end{array}$ & $\begin{array}{l}\text { Pesquisa quantitativa: questionários } \\
\text { estruturados (200) } \\
\text { Pesquisa qualitativa: exercícios } \\
\text { participativos }\end{array}$ \\
\hline
\end{tabular}




\begin{tabular}{|c|c|c|}
\hline $\begin{array}{l}\text { (Issoufou, } \\
\text { 2019) }\end{array}$ & $\begin{array}{l}\text { Examinar a importância do empreendedorismo e o papel } \\
\text { dos jovens empreendedores no desenvolvimento } \\
\text { econômico em países Islâmicos. }\end{array}$ & Pesquisa bibliográfica \\
\hline $\begin{array}{l}\text { (Sarti et al., } \\
\text { 2019) }\end{array}$ & $\begin{array}{l}\text { Investiga a orientação para o mundo de vida e explora a } \\
\text { vida quotidiana das crianças que cresceram em } \\
\text { contextos de pobreza a partir das suas próprias } \\
\text { perspectivas na Holanda. }\end{array}$ & $\begin{array}{l}\text { Pesquisa de Ação Participativa (29 } \\
\text { crianças): } \\
\text { Photovoice (principal) onde as } \\
\text { crianças tiraram fotos de coisas e } \\
\text { locais do seu ambiente local que } \\
\text { consideraram importantes, grupo } \\
\text { focal, entrevistas individuais, } \\
\text { observação dos participantes e análise } \\
\text { de conteúdo (temas emergentes) }\end{array}$ \\
\hline $\begin{array}{l}\text { (Inglis et al., } \\
\text { 2019) }\end{array}$ & $\begin{array}{l}\text { Identificar quais aspectos do estigma da pobreza são } \\
\text { particularmente salientes para indivíduos com } \\
\text { experiência vivida de pobreza e, portanto, podem } \\
\text { contribuir para as desigualdades na saúde na Escócia. }\end{array}$ & $\begin{array}{l}5 \text { Grupos focais com } 39 \text { indivíduos } \\
\text { com baixos rendimentos; Guia } \\
\text { temático semi-estruturado para } \\
\text { explorar como os participantes } \\
\text { definiram e compreenderam a pobreza } \\
\text { e o estigma. }\end{array}$ \\
\hline $\begin{array}{l}\text { (Zamora- } \\
\text { Sarabia et al., } \\
\text { 2019) }\end{array}$ & $\begin{array}{l}\text { Caracterizar as famílias em situação de insegurança } \\
\text { alimentar com crianças menores de } 18 \text { anos na Espanha. } \\
\text { Em particular, destacar os aspectos sociais e } \\
\text { institucionais que influenciam e interagem com as } \\
\text { tentativas dos pais para proteger os seus filhos da fome } \\
\text { e da miséria. }\end{array}$ & $\begin{array}{l}\text { Observação participante ( } 7 \text { meses). } \\
\text { Entrevistas em profundidade (15) com } \\
\text { análise de conteúdo com os pais das } \\
\text { crianças atendidas pelo banco de } \\
\text { alimentos autogerido. }\end{array}$ \\
\hline $\begin{array}{l}\text { (Possick, } \\
\text { 2019) }\end{array}$ & $\begin{array}{l}\text { Explorar os significados que as mulheres israelenses } \\
\text { que frequentam as cozinhas de sopa atribuem a esta } \\
\text { experiência. }\end{array}$ & $\begin{array}{l}\text { Observação dos participantes e } \\
\text { entrevistas com mulheres } \\
\text { participantes de cozinhas de sopa. } \\
\text { Método da Teoria Fundamentada para } \\
\text { delineamento, coleta de dados e } \\
\begin{array}{l}\text { análise das respostas dos } \\
\text { participantes. }\end{array}\end{array}$ \\
\hline $\begin{array}{l}\text { (Kabuye \& } \\
\text { Mukasa, } \\
\text { 2019) }\end{array}$ & $\begin{array}{l}\text { Explorar a compreensão das pessoas idosas sobre a } \\
\text { pobreza e analisar suas experiências com as políticas } \\
\text { governamentais de combate à pobreza }\end{array}$ & $\begin{array}{l}\text { Grupos focais e entrevistas com } \\
\text { informantes-chave, pessoas idosas em } \\
\text { situação de pobreza. Análise temática } \\
\text { e observação da comunicação não } \\
\text { verbal. }\end{array}$ \\
\hline $\begin{array}{l}\text { (Shong et al., } \\
\text { 2019) }\end{array}$ & $\begin{array}{l}\text { Examinar os efeitos da pobreza sobre o caráter } \\
\text { delinquente e o desenvolvimento comportamental das } \\
\text { crianças em três grandes temas que aumentam a } \\
\text { criminalidade - condições familiares miseráveis, } \\
\text { fracasso escolar e associação com colegas desviados - } \\
\text { para obter uma visão mais ampla de como a pobreza } \\
\text { poderia influenciar sua trajetória de vida. }\end{array}$ & $\begin{array}{l}\text { Entrevistas em profundidade. } \\
\text { Observação, estudo aprofundado de } \\
\text { casos e análise de documentos sobre a } \\
\text { experiência de vida de jovens } \\
\text { infratores de baixa renda. Análise } \\
\text { temática das respostas dos } \\
\text { entrevistados. }\end{array}$ \\
\hline $\begin{array}{l}\text { (Rose \& } \\
\text { McAuley, } \\
\text { 2019) }\end{array}$ & $\begin{array}{l}\text { Relatos das experiências vividas dos pais em situação de } \\
\text { pobreza são examinados em quatro estudos qualitativos } \\
\text { do Reino Unido publicados no período 1998-2016. }\end{array}$ & $\begin{array}{l}\text { Análise documental de pesquisas } \\
\text { sobre as experiências de pais em } \\
\text { situação de pobreza. }\end{array}$ \\
\hline $\begin{array}{l}\text { (Andresen \& } \\
\text { Meiland, } \\
\text { 2019) }\end{array}$ & $\begin{array}{l}\text { Relata os resultados da pesquisa qualitativa sobre a } \\
\text { pobreza com crianças na Alemanha. }\end{array}$ & $\begin{array}{l}\text { Observação participante, entrevistas } \\
\text { coletivas e individuais e discussões } \\
\text { em grupo sobre a experiência de } \\
\text { pobreza infantil. }\end{array}$ \\
\hline $\begin{array}{c}\text { (Fattore \& } \\
\text { Fegter, 2019) }\end{array}$ & $\begin{array}{l}\text { Reconstruir as práticas de distinção de classe das } \\
\text { crianças para explorar como a pobreza pode ser } \\
\text { entendida em termos de classe relacional e através de } \\
\text { práticas subjetivas de classe. O objetivo deste trabalho é } \\
\text { fornecer um conjunto de considerações teóricas sobre as } \\
\text { crianças como sujeitos de classe. }\end{array}$ & $\begin{array}{l}\text { Entrevistas com crianças e análise } \\
\text { temática das respostas dos } \\
\text { participantes. Desenhos de limites por } \\
\text { meio da reconstrução das experiências } \\
\text { dos participantes. }\end{array}$ \\
\hline $\begin{array}{l}\text { (Fiseha et al., } \\
\text { 2019) }\end{array}$ & $\begin{array}{l}\text { Investigar o papel do empreendedorismo rural na } \\
\text { redução da pobreza na província do Cabo Oriental. }\end{array}$ & $\begin{array}{l}\text { Questionários aplicados } \\
\text { proprietários de pequenas empresas e } \\
\text { análise descritiva das respostas dos } \\
\text { participantes. }\end{array}$ \\
\hline
\end{tabular}




\begin{tabular}{|c|c|c|}
\hline $\begin{array}{c}\text { (Silva, } \\
\text { Segatto, \& } \\
\text { Sousa, 2019) }\end{array}$ & $\begin{array}{l}\text { Que estratégias ajudariam a aproximar os } \\
\text { empreendimentos de inovação social das comunidades } \\
\text { pobres? }\end{array}$ & $\begin{array}{l}\text { Análise documental e observação não } \\
\text { participante. } \\
\text { semiestruturadas com beneficiários de } \\
\text { baixa renda de um programa de } \\
\text { habitação, com o proprietário e } \\
\text { funcionários da empresa prestadora do } \\
\text { serviço. Análise temática das } \\
\text { respostas dos participantes. }\end{array}$ \\
\hline $\begin{array}{l}\text { (Petrova \& } \\
\text { Simcock, } \\
\text { 2019) }\end{array}$ & $\begin{array}{l}\text { Examinar as dimensões de gênero no uso e privação de } \\
\text { energia doméstica. }\end{array}$ & $\begin{array}{l}\text { Pesquisa documental de artigos } \\
\text { científicos sobre a privação de energia } \\
\text { residencial e consequente situação de } \\
\text { pobreza vivenciada pelas famílias. }\end{array}$ \\
\hline $\begin{array}{l}\text { Morrow \& } \\
\text { Crivello, } \\
\text { 2015) }\end{array}$ & $\begin{array}{l}\text { Explorar como a pesquisa internacional de } \\
\text { desenvolvimento pode ser reforçada pela inclusão da } \\
\text { pesquisa qualitativa longitudinal (QLR). }\end{array}$ & $\begin{array}{l}\text { Pesquisa documental sobre uso de } \\
\text { Pesquisa Qualitativa Longitudinal na } \\
\text { compreensão do desenvolvimento } \\
\text { crianças e jovens pobres de países em } \\
\text { desenvolvimento. }\end{array}$ \\
\hline $\begin{array}{l}\text { (Simpson et } \\
\text { al., 2015) }\end{array}$ & $\begin{array}{l}\text { Trazer à luz como os profissionais da Educação e } \\
\text { Cuidados da Primeira Infância (ECEC) em toda a } \\
\text { Inglaterra se envolveram em discussões políticas e } \\
\text { adotaram expectativas relativas ao seu lugar na } \\
\text { abordagem da pobreza infantil. }\end{array}$ & $\begin{array}{l}\text { Investigação } r \text { qualitativa } \\
\text { fenomenológica e entrevistas com } \\
\text { profissionais da educação pré-escolar } \\
\text { que trabalhavam com famílias e } \\
\text { crianças em situação de pobreza. }\end{array}$ \\
\hline $\begin{array}{l}\text { (Fahmy et al., } \\
\text { 2015) }\end{array}$ & $\begin{array}{l}\text { Investigar a contribuição dos métodos qualitativos na } \\
\text { compreensão da opinião pública sobre as necessidades e } \\
\text { discutir as suas implicações para a medição da pobreza } \\
\text { com base em questionários. }\end{array}$ & $\begin{array}{l}\text { Pesquisa documental e análise de } \\
\text { conteúdo de documentos oficiais e } \\
\text { pesquisas de especialistas sobre } \\
\text { formas de percepção e conceituação } \\
\text { da pobreza. }\end{array}$ \\
\hline $\begin{array}{l}\text { (Kabir \& } \\
\text { Maitrot, } \\
\text { 2019) }\end{array}$ & $\begin{array}{l}\text { Compreender e abordar os fatores que afetam o } \\
\text { progresso nas intervenções de combate à pobreza. }\end{array}$ & $\begin{array}{l}\text { Grupos focais. Estudos de caso de } \\
\text { famílias beneficiárias de um programa } \\
\text { nacional de alívio da pobreza extrema. } \\
\text { Análise temática das respostas dos } \\
\text { participantes. }\end{array}$ \\
\hline $\begin{array}{l}\text { (Ceresola, } \\
\text { 2015) }\end{array}$ & $\begin{array}{l}\text { Investigar como os membros dos serviços nacionais } \\
\text { lidam com a vida abaixo da linha da pobreza. }\end{array}$ & $\begin{array}{l}\text { Entrevistas com membros de uma } \\
\text { organização } \\
\text { ofertante } \\
\text { oportunidades de serviços voluntários } \\
\text { remunerados. Análise temática das } \\
\text { respostas dos participantes. }\end{array}$ \\
\hline $\begin{array}{l}\text { (Jahan et al., } \\
\text { 2015) }\end{array}$ & $\begin{array}{l}\text { Compreender a natureza e os caminhos da "resiliência } \\
\text { das pessoas pobres". }\end{array}$ & $\begin{array}{l}\text { Pesquisa qualitativa documental. } \\
\text { Observação de pessoas pobres em } \\
\text { situação de vulnerabilidade por causa } \\
\text { da volatilidade de preços de } \\
\text { alimentos. }\end{array}$ \\
\hline $\begin{array}{l}\text { (Zainudin \& } \\
\text { Kamarudin, } \\
\text { 2015) }\end{array}$ & $\begin{array}{l}\text { Identificar o impacto da implementação de intervenções } \\
\text { sociais trazidas através de esquemas de microcrédito de } \\
\text { programas de alívio da pobreza para o bem-estar da } \\
\text { sociedade na Malásia e Indonésia. }\end{array}$ & $\begin{array}{l}\text { Questionários e entrevistas } \\
\text { semiestruturadas com pessoas pobres, } \\
\text { e análise documental de relatórios } \\
\text { anuais, documentários, livros, teses e } \\
\text { trabalhos de seminários. }\end{array}$ \\
\hline $\begin{array}{l}\text { (Sripanich et } \\
\text { al., 2015) }\end{array}$ & $\begin{array}{l}\text { Investigar os mecanismos de financiamento comunitário } \\
\text { de nível municipal conhecido como Fundo de } \\
\text { Desenvolvimento da Cidade (CDF), estabelecido na } \\
\text { Tailândia. }\end{array}$ & $\begin{array}{l}\text { Revisão histórica de documentos } \\
\text { oficiais, entrevista em profundidade e } \\
\text { grupos focais com representantes de } \\
\text { comitês para o desenvolvimento e } \\
\text { líderes comunitários, observação } \\
\text { participante e pesquisa de campo. }\end{array}$ \\
\hline $\begin{array}{l}\text { (Xu et al., } \\
\text { 2018) }\end{array}$ & $\begin{array}{l}\text { Investigar as múltiplas dimensões do alívio da pobreza } \\
\text { de mulheres por meio do empreendedorismo turístico na } \\
\text { China rural. }\end{array}$ & \begin{tabular}{llr} 
Entrevistas & \multicolumn{2}{c}{ semiestruturadas } \\
observação participante. Análise \\
temática das respostas dos \\
participantes.
\end{tabular} \\
\hline $\begin{array}{l}\text { (García \& } \\
\text { Ritterbusch, } \\
\text { 2015) }\end{array}$ & $\begin{array}{l}\text { Desenvolvimento de um índice multidimensional de } \\
\text { pobreza infantil na Colômbia. }\end{array}$ & $\begin{array}{l}\text { Grupos focais, foto-elucidação e } \\
\text { relatos de crianças e adolescentes } \\
\text { pobres sobre suas experiências de }\end{array}$ \\
\hline
\end{tabular}




\begin{tabular}{|c|c|c|}
\hline & & $\begin{array}{l}\text { vida. Entrevistas semiestruturadas } \\
\text { com especialistas. }\end{array}$ \\
\hline $\begin{array}{l}\text { (Mayombe, } \\
\text { 2018) }\end{array}$ & $\begin{array}{l}\text { Analisar como os graduados dos Programas de } \\
\text { Educação e Treinamento de Adultos (AET) perceberam } \\
\text { o impacto dos programas em suas condições de vida } \\
\text { após a graduação, a obtenção de empregos remunerados } \\
\text { ou a criação de suas próprias microempresas. }\end{array}$ & $\begin{array}{l}\text { Entrevistas semiestruturadas com } \\
\text { graduados de Programas de Educação } \\
\text { e Treinamento de Adultos. Análise } \\
\text { temática das respostas dos } \\
\text { participantes. }\end{array}$ \\
\hline $\begin{array}{l}\text { (Thompson et } \\
\text { al., 2018) }\end{array}$ & $\begin{array}{l}\text { Relata um estudo qualitativo sobre os desafios de saúde } \\
\text { e bem-estar da pobreza alimentar e dos bancos de } \\
\text { alimentos em Londres. }\end{array}$ & $\begin{array}{l}\text { Investigação etnográfica com } \\
\text { funcionários e usuários dos bancos de } \\
\text { alimentos; Entrevistas com as partes } \\
\text { interessadas da área de saúde, } \\
\text { funcionários e usuários do banco de } \\
\text { alimentos. }\end{array}$ \\
\hline (Ioris, 2016) & $\begin{array}{l}\text { Examina processos sinergéticos que formam a geografia } \\
\text { persistente de pobreza da região amazônica. }\end{array}$ & $\begin{array}{l}\text { Entrevistas semiestruturadas e } \\
\text { observação participante. Análise de } \\
\text { documentos oficiais e de políticas, e } \\
\text { workshops regionais. }\end{array}$ \\
\hline $\begin{array}{l}\text { (Kulb et al., } \\
\text { 2016) }\end{array}$ & $\begin{array}{l}\text { Examinar processo de empoderamento das mulheres por } \\
\text { meio de um grupo comunitário de microcrédito. }\end{array}$ & $\begin{array}{l}\text { Entrevistas e observações qualitativas } \\
\text { e aprofundadas para entender o } \\
\text { processo de empoderamento na } \\
\text { perspectiva de mulheres envolvidas } \\
\text { em um grupo de microcrédito } \\
\text { comunitário. }\end{array}$ \\
\hline $\begin{array}{l}\text { (Turner \& } \\
\text { Juntune, } \\
\text { 2018) }\end{array}$ & $\begin{array}{l}\text { Analisar a experiência de alunos de pós-graduação que } \\
\text { passaram por experiências de pobreza na infância. }\end{array}$ & $\begin{array}{l}\text { Entrevistas em profundidade com } \\
\text { alunos de pós-graduação que tiveram } \\
\text { experiências de pobreza durante a } \\
\text { infância. Desenvolvimento de diário } \\
\text { reflexivo e análise temática sobre as } \\
\text { respostas dos participantes. }\end{array}$ \\
\hline $\begin{array}{l}\text { (Strier et al., } \\
\text { 2016) }\end{array}$ & $\begin{array}{l}\text { Explorar os pontos de vista dos trabalhadores árabes e } \\
\text { judeus de baixa renda sobre a pobreza. }\end{array}$ & $\begin{array}{l}\text { Entrevistas em profundidade com } \\
\text { homens trabalhadores de baixa renda. } \\
\text { Análise temática das respostas dos } \\
\text { entrevistados. }\end{array}$ \\
\hline $\begin{array}{l}\text { (Ali et al., } \\
\text { 2017) }\end{array}$ & $\begin{array}{l}\text { Determinar a eficácia dos programas de microfinanças e } \\
\text { os fatores que contribuem para o alto nível de pobreza } \\
\text { entre os beneficiários de microfinanças no distrito de } \\
\text { Bogra, Bangladesh. }\end{array}$ & $\begin{array}{l}\text { Entrevistas com presidentes } \\
\text { (especialistas) de programas de } \\
\text { microfinanças. Discussões em grupo e } \\
\text { análise temática das falas dos } \\
\text { participantes. }\end{array}$ \\
\hline $\begin{array}{l}\text { (Gowayed, } \\
\text { 2018) }\end{array}$ & $\begin{array}{l}\text { Examinar o impacto de um programa de alívio da } \\
\text { pobreza, uma transferência condicionada de renda } \\
\text { (CCT) que tentou incentivar mães pobres, através de } \\
\text { uma transferência direta de renda, a enviar seus filhos à } \\
\text { escola. }\end{array}$ & $\begin{array}{l}\text { Dados etnográficos, aplicação de } \\
\text { questionários e entrevistas com mães } \\
\text { de alunos beneficiários de um } \\
\text { programa de transferência de renda. } \\
\text { Observação de discussões em grupos } \\
\text { focais. Entrevistas com especialistas e } \\
\text { observação de campo. }\end{array}$ \\
\hline $\begin{array}{l}\text { (Gunhidzirai } \\
\text { et al., 2017) }\end{array}$ & $\begin{array}{l}\text { Explorar a eficácia dos subsídios de apoio à criança no } \\
\text { alívio da pobreza. }\end{array}$ & $\begin{array}{l}\text { Entrevistas com assistentes sociais e } \\
\text { discussões em grupos focais com } \\
\text { beneficiários de subsídio de } \\
\text { Segurança Social. Análise temática } \\
\text { das respostas dos participantes. }\end{array}$ \\
\hline $\begin{array}{c}\text { (Anaafo \& } \\
\text { Guba, 2017) }\end{array}$ & $\begin{array}{l}\text { Analisar até que ponto as reformas agrárias estão } \\
\text { permitindo ou inibindo os pobres usuários de terra no } \\
\text { Gana de sair da pobreza e melhorar seus padrões de } \\
\text { vida. }\end{array}$ & $\begin{array}{l}\text { Realizaram entrevistas para uma } \\
\text { análise das experiências vividas por } \\
\text { mulheres agricultoras, pastoras e } \\
\text { agricultores migrantes, que fizeram } \\
\text { parte de um processo de reforma } \\
\text { agrária. Utilizaram observação de } \\
\text { fotografias para categorizar a } \\
\text { percepção dos entrevistados. } \\
\text { Realizaram análise de documentos } \\
\text { oficiais sobre a temática pesquisada. }\end{array}$ \\
\hline
\end{tabular}




\begin{tabular}{|c|c|c|}
\hline & & 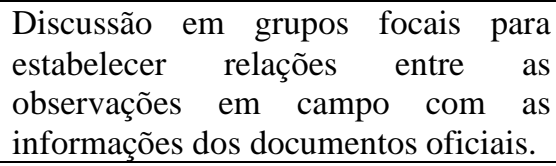 \\
\hline $\begin{array}{l}\text { (Alexander et } \\
\text { al., 2017) }\end{array}$ & $\begin{array}{l}\text { Analisa a lógica do Estudo Nacional de Pobreza (NPS) } \\
\text { e discute como ele pode informar pesquisas e políticas } \\
\text { sobre pobreza nas pequenas cidades, comunidades } \\
\text { suburbanas e bairros do interior dos Estados Unidos, por } \\
\text { meio de um Censo Qualitativo. }\end{array}$ & $\begin{array}{l}\text { Propõe um Censo Qualitativo baseado } \\
\text { no Estudo Nacional de Pobreza, uma } \\
\text { forma híbrida que combine o melhor } \\
\text { das abordagens qualitativas e } \\
\text { quantitativas. }\end{array}$ \\
\hline $\begin{array}{l}\text { (Omobowale } \\
\text { \& Akinola, } \\
\text { 2017) }\end{array}$ & $\begin{array}{l}\text { Comparar os dados oficiais e qualitativos sobre o } \\
\text { programa Fadama do Estado de Osun, Nigéria. }\end{array}$ & $\begin{array}{l}\text { Entrevistas com informantes-chave, } \\
\text { entrevistas em profundidade e } \\
\text { discussões de grupos focais. }\end{array}$ \\
\hline $\begin{array}{l}\text { (Dube et al., } \\
\text { 2018) }\end{array}$ & $\begin{array}{l}\text { Estabelecer o impacto das cheias no desenvolvimento } \\
\text { das comunidades rurais, analisar como a pobreza se } \\
\text { manifesta nas comunidades rurais, analisar a relação que } \\
\text { existe entre as cheias e a pobreza e sugerir formas de } \\
\text { lidar com os dois problemas. }\end{array}$ & $\begin{array}{l}\text { Entrevistas e observações de } \\
\text { comunidades rurais da província de } \\
\text { Tsholotsho, com pessoas pobres que } \\
\text { sofreram perdas por consequência de } \\
\text { inundações. Realizaram observações e } \\
\text { apontamentos sobre as experiências } \\
\text { vividas pelos entrevistados. }\end{array}$ \\
\hline $\begin{array}{l}\text { (Hamenoo et } \\
\text { al., 2018) }\end{array}$ & $\begin{array}{l}\text { Investigou experiências de trabalho infantil de crianças } \\
\text { que vendiam às margens de uma rodovia em Accra, } \\
\text { Gana. Especificamente, explorou as razões pelas quais } \\
\text { as crianças estavam envolvidas em trabalho infantil e de } \\
\text { que forma o trabalho infantil afetou a educação e a } \\
\text { saúde das crianças. }\end{array}$ & $\begin{array}{l}\text { Concepção qualitativa como meio de } \\
\text { explorar e compreender o trabalho } \\
\text { infantil. } \\
\text { Entrevistas em profundidade com } \\
\text { crianças e informantes-chave } \\
\text { (professores, pais, assistentes sociais, } \\
\text { membro da assembleia da zona, pastor } \\
\text { cristão e uma 'rainha' do mercado } \\
\text { local); } \\
\text { Dados das entrevistas analisados } \\
\text { tematicamente. }\end{array}$ \\
\hline $\begin{array}{l}\text { (Fenwick, } \\
\text { 2017) }\end{array}$ & $\begin{array}{l}\text { Delinear os desafios iniciais enfrentados pela agenda } \\
\text { emergente de investimentos sociais no Brasil, } \\
\text { juntamente com suas principais restrições políticas. }\end{array}$ & $\begin{array}{l}\text { Pesquisa qualitativa que inclui análise } \\
\text { da mídia, entrevistas semi- } \\
\text { estruturadas com elites locais, } \\
\text { representantes de ONGs e } \\
\text { especialistas brasileiros em política. }\end{array}$ \\
\hline $\begin{array}{l}\text { (Caplan et al., } \\
\text { 2017) }\end{array}$ & $\begin{array}{l}\text { Identificar qualitativamente temas emergentes sobre as } \\
\text { experiências vividas de pobreza de pessoas que } \\
\text { relataram ser pobres ou ter sido pobres, usando posts } \\
\text { selecionados nas mídias sociais. }\end{array}$ & $\begin{array}{l}\text { Coletados comentários de pessoas que } \\
\text { responderam sobre sua experîencia de } \\
\text { pobreza nas postagens na rede social } \\
\text { Reddit. Analisados } 1.495 \text { comentários, } \\
\text { por meio de uma avaliação de } \\
\text { palavras, frases e conceitos } \\
\text { pertinentes à questão da pesquisa. } \\
\text { Utilizada a análise temática } \\
\text { suplementar recomendada por Ryan e } \\
\text { Bernand (2003). Utilizado o software } \\
\text { NVivo } 10 \text { da QSR International para } \\
\text { análises e codificação. }\end{array}$ \\
\hline
\end{tabular}

Fonte: Resultados da pesquisa (2020).

\section{Considerações Finais}

A partir dos resultados dessa pesquisa compreendeu-se que o estudo da temática pobreza, por meio de abordagens qualitativas, permitiu o entendimento em profundidade das experiências e comportamentos dos indivíduos ou grupos investigados, pois as técnicas, proporcionaram aos pesquisadores sua aproximação com a realidade e expressões do 
cotidiano social e a partir desse lugar realizar a atividade de reflexão e construção das suas percepções sobre o objeto/problema de pesquisa.

Nas publicações que compõem o portfólio dessa pesquisa a temática da pobreza foi investigada a partir da visão de diversos atores, porém pôde-se observar que três grupos de indivíduos foram mais recorrentes nessas investigações: crianças, mulheres e idosos. Nesse sentido, nos estudos sobre pobreza foi construído o entendimento das vivências dos grupos mais vulneráveis com objetivo de contribuir com a formulação de estratégias de redução das situações degradantes a que esses sujeitos estão expostos.

Constatou-se que houve um aumento no número de publicações sobre pobreza com abordagens qualitativas nos últimos cinco anos. Assim, demonstra-se que houve uma evolução da disponibilidade de informações a respeito do tema. Esta pesquisa contribuiu com os pesquisadores da temática pobreza e áreas afins ao disponibilizar uma coleção de estudos que possibilitam o direcionamento e estruturação de problemas de pesquisa a partir de abordagens qualitativas.

A complementaridade dos métodos quantitativo e qualitativos de pesquisa é sugerida, haja vista que ambos possuem vantagens e desvantagens, e o uso da abordagem mista (quantitativa-qualitativa), adequada ao problema e objetivos da pesquisa, pode fomentar análises mais abrangentes sobre a complexidade e multidimensionalidade característicos do fenômeno da pobreza, e contribuir com a construção de estratégias mais efetivas no alívio da pobreza.

\section{Referências}

Alexander, J. T., Andersen, R., Cookson, P. W., Edin, K., Fisher, J., Grusky, D. B., Mattingly, M., \& Varner, C. (2017). A Qualitative Census of Rural and Urban Poverty. Annals of the American Academy of Political and Social Science, 672(1), 143-161. https://doi.org/10.1177/0002716217714156

Ali, I., Hatta, Z. A., Azman, A., \& Islam, S. (2017). Microfinance as a Development and Poverty Alleviation Tool in Rural Bangladesh: A Critical Assessment. Asian Social Work and Policy Review, 11(1), 4-15. https://doi.org/10.1111/aswp.12106

Anaafo, D., \& Guba, B. (2017). Do land reforms have adverse impacts on the livelihoods of poor land users? Evidence from the Nkoranza South Municipality, Ghana. Canadian Journal of African Studies, 51(2), 293-318. https://doi.org/10.1080/00083968.2017.1303390

Andresen, S., \& Meiland, S. (2019). Being poor from children's point of view. The potential 
of childhood theory and qualitative methods for child poverty research: Findings from two qualitative studies of poverty in Germany. Children and Youth Services Review, 97, 94-99. https://doi.org/10.1016/j.childyouth.2017.07.010

Aria, M., \& Cuccurullo, C. (2017). bibliometrix: An R-tool for comprehensive science mapping analysis. Journal of Informetrics, 11(4), 959-975.

https://doi.org/10.1016/j.joi.2017.08.007

Bauer, M. W., Gaskell, G., \& Allum, N. C. (2015). Qualidade, quantidade e interesses do conhecimento: evitando confusões. In M. W. Bauer \& G. GASKELL (Eds.), Pesquisa Qualitativa com texto, imagem e som: um manual prático (13th ed., pp. 17-36). Vozes.

Caplan, M. A., Purser, G., \& Kindle, P. A. (2017). Personal Accounts of Poverty: A Thematic Analysis of Social Media. Journal of Evidence-Informed Social Work, 14(6), 433-456. https://doi.org/10.1080/23761407.2017.1380547

Ceresola, R. (2015). Doing Poor in AmeriCorps: How National Service Members Deal With Living Below the Poverty Line Abstract. Qualitative Sociology Review, XI(4), 117-137.

Dube, E., Mtapuri, O., \& Matunhu, J. (2018). Flooding and poverty: Two interrelated social problems impacting rural development in Tsholotsho district of Matabeleland North province in Zimbabwe. Jamba: Journal of Disaster Risk Studies, 10(1), 1-7.

https://doi.org/10.4102/jamba.v10i1.455

Elango, B., \& Rajendran, P. (2014). Authorship Trends and Collaboration Pattern in the Marine Sciences Literature : A Scientometric Study. International Journal of Information Dissemination and Technology, 2, 166-169.

Fahmy, E., Sutton, E., \& Pemberton, S. (2015). Are we all agreed? Consensual methods and the "necessities of life" in the UK today. In Journal of Social Policy (Vol. 44, Issue 3, pp. 591-610). Cambridge University Press. https://doi.org/10.1017/S0047279415000033

Fattore, T., \& Fegter, S. (2019). Children, social class and social practices: A theoretical analysis of children's practices of class distinction. Children and Youth Services Review, 97, 67-75. https://doi.org/10.1016/j.childyouth.2017.06.032

Fenwick, T. B. (2017). From CCTs to a social investment welfare state? Brazil's 'new' propoor strategy. Development Policy Review, 35(5), 659-674. https://doi.org/10.1111/dpr.12247

Fiseha, G. G., Kachere, W., \& Oyelana, A. A. (2019). The role of rural entrepreneurship in alleviating poverty in the eastern cape. Journal of Human Ecology, 68(1-3), 203-212. https://doi.org/10.31901/24566608.2019/68.1-3.3191 
Franz, C. E., \& Cook, K. (2020). Utilisation of social determinants of health to improve education among youth in Dominican baseball academies. Health and Social Care in the Community, 28(2), 423-430. https://doi.org/10.1111/hsc.12874

García, S., \& Ritterbusch, A. (2015). Child Poverty in Colombia: Construction of a Multidimensional Measure Using a Mixed-Method Approach. Child Indicators Research, 8, 801-823. https://doi.org/10.1007/s12187-014-9274-2

Gowayed, H. (2018). The Unnecessary Nudge: Education and Poverty Policy in a Cairo Slum. Sociological Forum, 33(2), 482-504. https://doi.org/10.1111/socf.12421

Gunhidzirai, C., Makoni, M., \& Tanga, P. T. (2017). Child support grants and poverty reduction in hill crest community, Eastern Cape province of South Africa. Journal of Social Sciences, 51(1-3), 70-78. https://doi.org/10.1080/09718923.2017.1305572

Hamenoo, E. S., Dwomoh, E. A., \& Dako-Gyeke, M. (2018). Child labour in Ghana: Implications for children's education and health. Children and Youth Services Review, 93, 248-254. https://doi.org/10.1016/j.childyouth.2018.07.026

Inglis, G., McHardy, F., Sosu, E., McAteer, J., \& Biggs, H. (2019). Health inequality implications from a qualitative study of experiences of poverty stigma in Scotland. Social Science and Medicine, 232, 43-49. https://doi.org/10.1016/j.socscimed.2019.04.033

Ioris, A. A. R. (2016). The paradox of poverty in rich ecosystems: Impoverishment and development in the Amazon of Brazil and Bolivia. Geographical Journal, 182(2), 178-189. https://doi.org/10.1111/geoj.12124

Issoufou, C. (2019). Creation of young entrepreneurs as resources of economic development and alleviation of poverty in muslim countries: An Islamic approach. Humanities and Social Sciences Reviews, 7(5), 1060-1064. https://doi.org/10.18510/hssr.2019.75141

Jahan, F., Mamun-ur-Rashid, \& Wahab, S. A. (2015). The Role of Fatalism in Resilience to Food Price Volatility in Bangladesh. IDS Bulletin, 46(6), 60-67.

https://doi.org/10.1111/1759-5436.12187

Kabir, A., \& Louise Maitrot, M. R. (2019). Qualitative exploration of factors affecting progress in antipoverty interventions: Experiences from a poverty-reduction program in Bangladesh. Cogent Social Sciences, 5(1), 1-16.

https://doi.org/10.1080/23311886.2019.1602986 
Kabuye, R., \& Mukasa, N. (2019). Older people's conceptualisation of poverty and their experiences of government programmes in Uganda. Development in Practice, 29(3), 349359. https://doi.org/10.1080/09614524.2018.1552659

Kageyama, A. \& Hoffmann, R. (2006). Pobreza no Brasil: uma perspectiva multidimensional. Economia e Sociedade, 14(1 (26)), 79-112.

Korstjens, I., \& Moser, A. (2018). European Journal of General Practice Series: Practical guidance to qualitative research. Part 4: Trustworthiness and publishing. European Journal of General Practice, 24(1), 120-124. https://doi.org/10.1080/13814788.2017.1375092

Koseoglu, M. A. (2016). Mapping the institutional collaboration network of strategic management research: 1980-2014. Scientometrics, 109(1), 203-226.

Kulb, C., Hennink, M., Kiiti, N., \& Mutinda, J. (2016). How Does Microcredit Lead to Empowerment? A Case Study of the Vinya wa Aka Group in Kenya. Journal of International Development, 28(5), 715-732. https://doi.org/10.1002/jid.3130

MacDonald, R., Shildrick, T., \& Furlong, A. (2020). 'Cycles of disadvantage' revisited: young people, families and poverty across generations*. Journal of Youth Studies, 23(1), 12 27. https://doi.org/10.1080/13676261.2019.1704405

Mayombe, C. (2018). From social exclusion to adult education and training for community development in South Africa. Community Development, 49(4), 398-414. https://doi.org/10.1080/15575330.2018.1496942

Minayo, M. C. de S. (2017). Sampling and saturation in qualitative research: consensuses and controversies. Revista Pesquisa Qualitativa, 5(7), 1-12.

Moher, D., Liberati, A., Tetzlaff, J., \& Altman, D. G. (2012). Preferred reporting items for systematic reviews and meta-analyses: the PRISMA statement... Preferred Reporting Items for Systematic reviews and Meta-Analyses. BMJ: British Medical Journal (Overseas $\{\&\}$ Retired Doctors Edition), 8, b2535. https://doi.org/10.1016/j.ijsu.2010.02.007

Morais-da-Silva, R. L., Segatto, A. P., \& Bezerra-de-Sousa, I. G. (2019). Connecting Two Sides: A Qualitative Study on Social Innovation Ventures and Poor Communities in an Emerging Economy. Voluntas. https://doi.org/10.1007/s11266-019-00156-X

Morrow, V., \& Crivello, G. (2015). What is the value of qualitative longitudinal research with children and young people for international development? International Journal of Social Research Methodology, 18(3), 267-280. https://doi.org/10.1080/13645579.2015.1017903 
Ninsiima, A. B., Michielsen, K., Kemigisha, E., Nyakato, V. N., Leye, E., \& Coene, G. (2020). Poverty, gender and reproductive justice. A qualitative study among adolescent girls in Western Uganda. Culture, Health and Sexuality, 22(1), 1-15.

https://doi.org/10.1080/13691058.2019.1660406

Omobowale, A. O., \& Akinola, O. T. (2017). A contextual assessment of the FADAMA III programme in Iwo, Osun State, Nigeria. African Journal of Science, Technology, Innovation and Development, 9(4), 479-488. https://doi.org/10.1080/20421338.2017.1352122

Petrova, S., \& Simcock, N. (2019). Gender and energy: domestic inequities reconsidered. Social and Cultural Geography, 1-19. https://doi.org/10.1080/14649365.2019.1645200

Possick, C. (2019). Women who frequent soup kitchens: A cultural, gender-mainstreaming perspective. Journal of Social Work, 19(3), 397-414.

https://doi.org/10.1177/1468017318765993

Rocha, S. (2006). Pobreza no Brasil: afinal, de que se trata? (2nd ed.). Editora FGV.

Rose, W., \& McAuley, C. (2019). Poverty and its impact on parenting in the UK: Re-defining the critical nature of the relationship through examining lived experiences in times of austerity. Children and Youth Services Review, 97(July 2017), 134-141.

https://doi.org/10.1016/j.childyouth.2017.10.021

Sarti, A., Dedding, C., \& Bunders, J. F. G. (2019). Beyond a deficiencies approach: Towards a more integral representation of the everyday life of children growing up in contexts of poverty. Qualitative Social Work, 18(5), 818-833.

https://doi.org/10.1177/1473325018768391

Sewell, S. J., Desai, S. A., Mutsaa, E., \& Lottering, R. T. (2019). A comparative study of community perceptions regarding the role of roads as a poverty alleviation strategy in rural areas. Journal of Rural Studies, 71, 73-84. https://doi.org/10.1016/j.jrurstud.2019.09.001

Shong, T. S., Abu Bakar, S. H., \& Islam, M. R. (2019). Poverty and delinquency: A qualitative study on selected juvenile offenders in Malaysia. International Social Work, 62(2), 965-979. https://doi.org/10.1177/0020872818756172

Silva, A. M. R., Lacerda, F. C. C., \& Neder, H. D. (2011). A evolução do estudo da pobreza: da abordagem monetária à privação de capacitações. Bahia Análise \& Dados, 21(3), 509-527.

Simpson, D., Lumsden, E., \& Clark, R. M. D. (2015). Pre-school practitioners, child poverty 
and social justice. International Journal of Sociology and Social Policy, 35(5-6), 325-339. https://doi.org/10.1108/IJSSP-10-2013-0101

Sripanich, B., Nitivattananon, V., \& Perera, R. (2015). City development fund: A financial mechanism to support housing and livelihood needs of Thailand's urban poor. Habitat International, 49, 366-374. https://doi.org/10.1016/j.habitatint.2015.05.011

Strier, R., Eisikovits, Z., Sigad, L., \& Buchbinder, E. (2016). Working Men Views of Poverty: Ethnic Perspectives. Men and Masculinities, 19(5), 480-502.

https://doi.org/10.1177/1097184X15613829

The World Bank (2018). Poverty and shared prosperity: piecing together the poverty puzzle. https://doi.org/10.1596/978-1-4648-1330-6

Thompson, C., Smith, D., \& Cummins, S. (2018). Understanding the health and wellbeing challenges of the food banking system: A qualitative study of food bank users, providers and referrers in London. Social Science and Medicine, 211, 95-101.

https://doi.org/10.1016/j.socscimed.2018.05.030

Turner, J. S., \& Juntune, J. (2018). Perceptions of the Home Environments of Graduate Students Raised in Poverty. Journal of Advanced Academics, 29(2), 91-115. https://doi.org/10.1177/1932202X18758259

Tuzzo, S. A., \& Braga, C. F. (2016). O processo de triangulação da pesquisa qualitativa: o metafenômeno como gênese. Revista Pesquisa Qualitativa, 4(5), 140-158. https://editora.sepq.org.br/index.php/rpq/article/view/38/31

Xu, H., Wang, C., Wu, J., Liang, Y., Jiao, Y., \& Nazneen, S. (2018). Human Poverty Alleviation through Rural Women's Tourism Entrepreneurship. Journal of China Tourism Research, 14(4), 445-460. https://doi.org/10.1080/19388160.2018.1507860

Zainudin, M. Z., \& Kamarudin, M. F. (2015). Impacts on the implementation of social policy: Comparative study in Malaysia and Indonesia. Asian Social Science, 11(17), 48-56. https://doi.org/10.5539/ass.v11n17p48

Zamora-Sarabia, A. L., Guterman, R. H., Sanz-Barbero, B., Rico Gómez, A., \& Otero García, L. (2019). Child health and the possibilities for childcare in a context of poverty and food insecurity: The narratives of parents attending a self-managed foodbank in Spain. Health and Social Care in the Community, 27(4), 953-964. https://doi.org/10.1111/hsc.12712 
Research, Society and Development, v. 9, n. 7, e911974183, 2020

(CC BY 4.0) | ISSN 2525-3409 | DOI: http://dx.doi.org/10.33448/rsd-v9i7.4183

Porcentagem de contribuição de cada autor no manuscrito

Francis Régis Gonçalves Mendes Barbosa - 40\%

Maiara de Oliveira Noronha $-40 \%$

Moacir Piffer $-20 \%$ 